\title{
BREACH OF CONFIDENTIALITY: UNINTENTIONAL COMMON PRACTICE DUE TO MISUNDERSTANDING AND UNAWARENESS
}

\author{
Mohammad Waseem Khan \\ Master Student of Bioethics, Aga Khan University Hospital, Karachi, Sindh, Pakistan. \\ Email: mwaseem.tareen@yahoo.com
}

\begin{abstract}
Advancement in medical technology has helped man kind in several ways and no one can deny the contribution of medical technology in the field of medicine. On the other hand technology has also given rise to some ethical issues. The issue of confidentiality is one of those issues. Patients keeping their trust on physician reveals all concerned confidential information to their physician with surety that physician will not reveal it to other person and will keep it confidential. It has been common in practice that, physicians unintentionally breach their patient's confidentiality by discussing cases and history of their patients in public places, hospital elevators, and with their students. In a busy hospital setting it can be difficult to maintain confidentiality for patients. Increasing workloads lead to discussions of patients in public areas which is not an acceptable excuse. The very next person present there listening the discussion could be a patient's friend, relative, or media member that is not entitled to this privileged information. In all these cases permission must be received from the patient prior to any disclosure.
\end{abstract}

Introduction: The principal of confidentiality involves sharing of information with the expectation that it will not be revealed to third parties, or that it will be revealed under restricted circumstances with consent of the owner. The principal of confidentiality is usually applied to private information of the patient which is an important aspect of privacy between patient-physician relationships. Health care professionals have a legal and ethical duty to keep patient's medical information private. Physicians and nurses, along with hospital staff are required by law and professional codes to practice confidentiality. ${ }^{1}$

Patients have right to expect that information about them will be held confidential in confidence by their doctors that is central to trust between doctors and patients. In our environment we see many tertiary care hospitals following the policy of confidentiality but still unable to follow it in practicality. There are number of cases in which patient's confidential information are shared in hospitals and public places by the physicians and the healthcare team.

The duty of physician includes the confidentiality of their patients which need physician not to disclose any medical information which is discovered by physician or revealed by patient to physician. The obligation of confidentiality can be breached in specific situation where benefit gain is greater than breach of confidentiality. Situations where confidentiality can be breached include public welfare and concern for the safety of other specific person. As far as the case which includes the breach of confidentiality for education and teaching purpose, care needs to be taken by avoiding common practice mentioning patient names. Patient's confidentiality can be maintained by not disclosing patient name and allotting identification numbers to patients and discussing each case by their identification number. Identification number will help maintaining patient confidentiality and achieving desired purpose of education to the medical students.

Case Study: In a tertiary care hospital (Quetta) a patient (X) after visiting his physician (D) came to know that his physician has breached his confidential information to the people while discussing the case with medical students for teaching purpose in consulting clinics. In consulting clinics there were some other patients with their relatives waiting for their meeting with the physician. The patient was told by one of his family member $(F)$ who was present in consulting clinic's waiting area as the physician was pointing him out with his name. The information revealed was meant to be confidential which the patient was unwilling to share with anybody else other than his physician.

Ethical Issue: Maintaining patient confidentiality is one of the most important columns in clinical practice. Physicians and health care providers have the duty of protecting the private details of their patient. Maintaining patient confidentiality is not just a matter of moral respect but is an essential element in retaining the important bond of trust between the physician and patients. Physicians are bound to obey and are governed by the rules of confidentiality. Physicians and health care providers can not reveal a patient's medical history, even to their closest family members or friends, without the permission of their patient. 
Analysis In Norman Daniels Framework: Now, I will try to unfold and asses the above case by following Accountability for reasonableness approach presented by Norman Daniel which is mainly based on justice and fair selection. Four main postulates of AFR include:

\section{Publicity}

\section{Relevance}

3. Appeals and revisions

4. Regulative (enforcement)

Publicity condition: As it is claimed by Norman Daniels that accountability for reasonableness makes decisions in healthcare legitimate and fair. The first condition of priority setting states that decisions and their rationales must be accessible to public. Applying accountability for reasonableness we see that in cases of protecting patient's confidentiality the hospitals has clear cut policy of applying the principal that follows the first condition of accountability for reasonableness and the policy is sometimes accessible and understand able to the public and some time it is not. It may be made easily accessible to the public by creating awareness programs to the public., 3 ,

Relevance condition: Applying the second condition of $A$ for $R$ in priority setting which states that rationales for priority setting and decisions making must rest on valid reasons. The patient's confidentiality is sometimes overruled by health care professionals which might not always be legal. Firstly it should be done with the permission of concerned patient and should be justified with greater ratio of benefits to risks. The relevant condition needs to be explained with reasonable explanation by health care provider to the patient whether that is to be discussed with another physician, family members or to the students for teaching purpose. ${ }^{2,3,4}$

Appeals and revisions condition: Moving to the third condition of $A$ for $R$, appeals and revisions should be welcomed by the organization in any case where the affected body thinks that the breach of confidentiality is not justified or if he shows any concern. For any process, appeals and revisions plays a pivotal role for future betterment

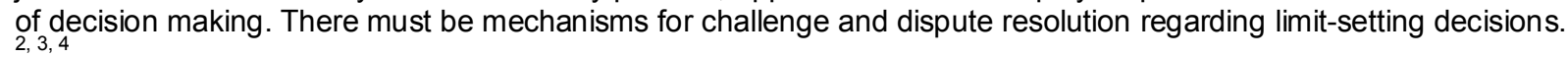

Regulative condition: As for as the fourth condition of $A$ for $\mathrm{R}$ is concerned a lot of mishaps occur there. Health care organizations do make the policies to follow the principal of confidentiality and to safeguard their patients, but it is not ensured that they are applying that policy in their day to day practice. In many cases it has been seen that health care professionals some way the other do breach their patient's confidentiality without knowing themselves. In many cases the confidential information has been discussed widely in public areas of the health care hospitals by the health care professionals and the team working in health care hospitals. $2,3,4$

Observational studies in tertiary care hospitals have shown that breaches of Patient's confidentiality by healthcare professionals occurred by discussing patients by name at parties or even in hospital elevators or cafeterias. Most healthcare professionals know the limits of confidentiality well but they have trouble applying them to their behavior as they are unintentionally involved in breaching their patient's confidentiality. 5

Beside the conditions of accountability for reasonableness for any action to be reasonable it must pass through relevant phases of responsibility, authority and accountability. As in cases of confidentiality the physicians are responsible for their patient confidentiality and if they are given the suitable environment and authority to accomplish their job then they should be accountable for the protection of their patient's confidentiality.

Conclusion: Maintaining confidentiality is increasingly difficult in modern medicine as many people have access to medical records, including the attending physician, house staff, medical students, consultants, nurses, social workers, pharmacists, billing staff and medical records but all possible measures should be taken to safe guard patient's confidential information to maintain the value of trust between patient and physician. As confidentiality is not only between the individual and the advisor but it is also between the individual and the organization for this reason a clear cut policy should be made by health care organization following the four conditions of accountability for reasonableness which will be helpful in avoiding breach of confidentiality and will ensure that decisions are made fairly. 


\section{References:}

1. Majumder M. "Cyberbanks and other virtual research repositories". Journal of Law, Medicine \& Ethics 2005. 33, 31.

2. Daniels N. "Accountability for reasonableness: Establishing a fair process for priority setting is easier than agreeing on principles". BMJ 2000;321:1300-1.

3. Daniels N, Sabin JE. "Limits to health care: fair procedures, democratic deliberation, and the legitimacy problem for insurers". Philos Public Aff 1997;26:303-50.

4. Rid A. "Justice and procedure: how does "accountability for reasonableness" result in fair limit-setting decisions"? J Med Ethics 2009 35: 12-16.

5. Vigod, SN. et al. "Privacy of patient's information in hospital lifts: observational study". BMJ 2003; 327:10245.

6. Bemard, Lo. "Resolving ethical dillemmas, a guide for clinicians". 4th edition. Chapter 5. Pp4-48.

7. Beauchamp TL, Childress JF. "Principles of biomedical ethics", 4th Ed. New York: Oxford University Press, 1994: 418-42. 